\title{
Como medir a variação de acessibilidade causa pela implantação de um território gerador de viagens?
}

\author{
Jessica Helena de Lima ${ }^{1}$, Maurício Oliveira de Andrade ${ }^{2}$ e Maria Leonor Alves Maia ${ }^{3}$
}

\begin{abstract}
Resumo: O aumento do número de deslocamentos causado pela implantação de um território gerador de viagens traz impactos ao ambiente urbano. A existência de uma ferramenta que torne possível mensurar essas variações, indicando onde acontecem com maior intensidade faz-se necessária, a fim de alertar ao poder público para a necessidade da realização de investimentos em transportes no local. Este trabalho analisa o impacto causado pelo novo Complexo Industrial Portuário de Suape em Pernambuco, considerado um território gerador de viagens, através de indicadores de acessibilidade. Para isto são utilizadas medições anteriores à existência do Complexo (1997), e da sua fase de implantação e operação de algumas indústrias em 2010. São observadas mudanças positivas e negativas na dinâmica local, como, por exemplo, o tempo de deslocamento dos moradores da região diminui, indicando que eles são em parte absorvidos pelo Complexo, por outro lado aumenta muito para quem se dirige pendularmente à região, indicando que as infraestruturas e os serviços de transportes disponíveis precisam ser melhorados.

Palavras-chave: indicador de acessibilidade; território gerador de viagens; deslocamento pendular.
\end{abstract}

\begin{abstract}
The increased number of displacements caused by a trip generator territory implantation brings impacts to the urban environment. The existence of a tool that makes it possible measuring variations by indicating where they occurred with greater intensity is needed to guide the government when making investments in local transport. This paper analyzes the impact caused by the new Suape's Industrial Port Complex, which is considered as a trip generator territory, throughout accessibility indicators. Thus measures prior to the complex existence (1997) and from deployment and operations stage of some industries in 2010 were used. Positive and negative changes on the local dynamics, e.g., commuting time for the region's inhabitants decreases indicating they were in part absorbed by the Complex, on the other side it increases greatly for those heading the region, indicating the transport services and infrastructure available need to be improved.
\end{abstract}

Keywords: accessibility indicator; trip generator territory; commuting.

\section{INTRODUÇÃO}

Cidades são entidades dinâmicas cujas transformações ocorridas ao longo do tempo têm forte relação com o transporte. Por se constituir em elemento importante na organização e estruturação do espaço urbano e regional, o transporte atua no crescimento e no desenvolvimento dos centros urbanos. Ao longo do tempo, a dinâmica econômica e urbana configura espaços de ascensão ou decadência socioambiental. Por um lado, há estímulos fiscais e econômicos para concentração de atividades em determinados territórios (novas áreas ou áreas em renovação) ou por outro, um esvaziamento de atividades econômicas, resultando em degradação urbana em áreas muitas vezes bem servidas de infraestrutura.

Não se pode deixar de mencionar os efeitos negativos e positivos dos casos onde o estímulo à concentração de atividades em áreas novas é também considerado como uma alavanca para o desenvolvimento e melhoria socioambiental de uma região. Esses efeitos normalmente impactam em áreas mais abrangentes do que aquela onde as atividades econômicas se concentram. Esse é o caso da implantação do

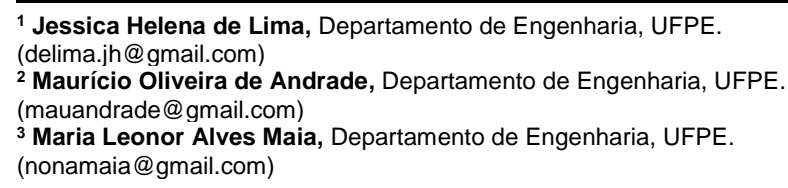

Complexo Industrial Portuário de Suape, localizado ao sul da Região Metropolitana de Recife, objeto da análise deste artigo.

Para Cunha et al. (2004), um dos condicionantes para a sustentabilidade de atividades socioeconômicas em áreas onde processos de renovação econômica estão presentes é a qualidade da acessibilidade aos serviços e equipamentos disponíveis nessa região. Argumenta-se que o reaquecimento da dinâmica econômica local decorre preponderantemente da implantação de novas atividades numa determinada área, cujos processos atrairão uma nova demanda de deslocamentos de indivíduos e de mercadorias. Dessa forma, se não forem oferecidas boas condições de acesso, mesmo tendo sido instaladas as atividades, o processo de renovação poderá ter sua sustentabilidade comprometida.

Esse é um fator a ser considerado em função dos vultosos investimentos (cerca de U\$ 17 bilhões) feitos no litoral sul da Região Metropolitana do Recife para a implantação do Complexo Industrial Portuário de Suape (CIPS), pois a dificuldade de acesso a essa região pode gerar um custo desnecessário às atividades operacionalizadas (PORTOGENTE, 2014). Rocha, Sales e Ramos (2007) previam que o trânsito intensificado de veículos e o crescimento urbanístico sem planejamento, seriam os dois principais impactos negativos previstos sobre a infraestrutura local. $\mathrm{O}$ aumento do número de deslocamentos para a região iniciouse desde a fase de implantação, prosseguindo na fase de operação, principalmente da Refinaria do Nordeste da Petrobrás (RNEST), o mais importante empreendimento em atração de viagens para a região. Esse e outros empreendimentos vêm exercendo pressão sobre a infraestrutura viária atual e promovendo desgastes principalmente na rodovia PE-060 e as vias internas de Suape, principais rodovias de 
acesso ao Complexo. Além da necessidade de acesso às atividades econômicas nessa região, o deslocamento e a migração da população em busca de emprego nessa área impõem pressão sobre a habitação e as infraestruturas de abastecimento de água, esgotamento sanitário, coleta de lixo e transportes, além de serviços básicos de educação, saúde e assistência social.

Pela concentração de atividades de grande porte e de suas características de cluster econômico, o Complexo de Suape pode ser caracterizado como um Território Gerador de Viagens - TGV, como já estudado por Meira et al. (2012), caracterizado por um conjunto de Polos Geradores de Viagens concentrados em um determinado território. Para a REDPGV (2010), Polos Geradores de Viagens (PGV) são empreendimentos que causam impacto no tráfego, no desenvolvimento econômico e na qualidade de vida da população. Outros autores desenvolveram denominações distintas para semelhante definição, como Goldner (2010), que define como Polos Múltiplos Geradores de Viagens (PMGVs), os conjuntos de estabelecimentos comerciais ou de serviços próximos entre si que formam clusters de atividades.

Avaliando do ponto de vista da diminuição da desigualdade e do aumento da qualidade de vida para a população local, Cavalcanti (2004) argumenta que a melhora não seria significante nos municípios que acolhem o CIPS, pois o deficiente nível da educação da rede pública estadual, não atenderia às exigências industriais e impossibilitaria a contratação de trabalhadores locais, agravando as profundas e históricas desigualdades sociais.

Nesse contexto, o objetivo deste trabalho é medir a variação na dinâmica das cidades por efeito do surgimento de um novo território gerador de viagens, tanto do ponto de vista da mobilidade, medida pela diferença no tempo de deslocamento, quanto do ponto de vista social, medido pelas variações nos volumes de deslocamento de trabalhadores entre os municípios. Essa análise é feita considerando as mudanças nos movimentos pendulares casa-trabalho entre o ano base de 1997 (antes da implantação do CIPS) e o ano de 2010. Foi desenvolvido um procedimento metodológico de análise, utilizando cortes transversais e longitudinais. Com base nos indicadores desenvolvidos por Mäcke (1974) e Wachs e Kumagai (1973), são propostos dois indicadores que permitem avaliar a relevância dos territórios geradores de viagens na conformação das centralidades urbanas e verificar quais grupos este novo polo beneficiou, do ponto de vista dos transportes, diminuindo o tempo de deslocamento, e socioeconômico, aumentando o número de empregos.

\section{POLOS GERADORES DE VIAGENS E ACESSIBILIDADE}

\subsection{Polo Gerador de Viagens}

A Rede Ibero-Americana de Estudo em Polos Geradores de Viagens define um PGV como:

"equipamentos potenciais geradores de impactos nos sistemas viários e de transportes (congestionamentos, acidentes e naturais repercussões no ambiente) como também no desenvolvimento socioeconômico e na qualidade de vida da população" (REDE, 2005).

Existem duas teorias que respaldam o conceito defendido pela REDE. A primeira diz respeito aos centros urba- nos e centralidades, segundo a qual, certos empreendimentos geradores de viagens atribuem per se características de centralidade à sua área de influência produzindo atividades e remodelando os padrões de uso e ocupação do solo, criando um agregado formado pelo empreendimento gerador de viagens e as atividades atraídas, cujas características de centralidade são capazes de compor subcentros ou centros regionais na área (REDPGV, 2010). Assumindo essa teoria de policentralidade, alguns estudiosos afirmam que ela proporciona numa diminuição do tempo e da distância das viagens pendulares (Levinson e Kumar, 1994; Gordon e Richardson, 1996; Schwanwn et al., 2001; Aguilera e Mignot, 2004; McMillen, 2004; Zhao, Lu e Roo., 2010; Lin, Allan e Cui, 2015). Entretanto, outros defendem que a policentralidade é negativa por aumentar o número de deslocamentos individuais motorizados (Cevero, 1996; Ewing, 1997; Cervero e Day, 2008). Para Schwanwn (2001), Aguilera e Mignot (2004) e Cervero e Day (2008) isso ocorre apenas se as infraestruturas de transporte público e o incentivo aos modos não motorizados não acompanharem as novas centralidades.

A segunda teoria que respalda o conceito de PGV denomina-se Teoria dos Polos de Desenvolvimento. Seu autor, Perroux (1962), afirma que o crescimento não surge simultaneamente em todos os lugares, ele se manifesta em pontos ou polos de crescimento, com diferentes intensidades e se transmite por meio de diversos canais e com implicações diversas para a economia. Desta forma, a organização do espaço acontece em setores e ao redor dos centros (polos), com determinadas características econômicas, políticas e culturais, gerando, assim, as regiões (no entorno dos centros) (Saquet, 2011). É possível aferir que o surgimento de um empreendimento gerador de viagens modifica seu meio geográfico próximo e a estrutura econômica de forma a assentar a intensificação das atividades econômicas em virtude das proximidades e dos contatos humanos. Para apresentar características de um polo gerador de desenvolvimento, um empreendimento gerador de viagens deve apresentar impactos positivos de longo prazo, proporcionando à zona de influência um crescimento sustentável. Similar argumento pode ser aplicado a territórios geradores de viagens, pela concentração, numa dada região, de grandes empreendimentos com características de PGVs.

\subsection{Acessibilidade}

Os problemas de mobilidade urbana mais significativos estão atrelados ao nível de acessibilidade de uma determinada zona. Um exemplo disso são as dificuldades advindas do crescimento populacional, via ensejo da expansão habitacional e da criação de empregos, dito que a atratividade do local onde se opta por habitar depende da existência de infraestrutura concomitantemente com a acessibilidade entre a residência e as diversas atividades que o cidadão desejar exercer (Sales Filho apud Cunha et al., 1996).

Sendo indispensável participar das atividades urbanas cotidianas e sabendo que inevitavelmente existe entre elas uma separação espacial, a acessibilidade às atividades certamente constitui um pilar fundamental para o desenvolvimento de uma cidade ou região. Visto que o acesso físico das pessoas aos lugares onde as atividades ocorrem é possibilitado por meios de transporte, o modo como a interação entre transporte e uso do solo acontece é o determinante de 
um maior ou menor nível de acessibilidade (Cunha et al., 2004).

Definições de acessibilidade são abundantes na literatura. Exemplos incluem a primeira e amplamente difundida "oportunidades potenciais de interação" (Hansen, 1959), "a liberdade dos indivíduos de decidir se desejam ou não participar em diferentes atividades" (Burns, 1979), “os benefícios providos por um sistema de transporte/uso do solo" (Ben-Akiva e Lerman, 1979) e "indicadores do impacto do desenvolvimento uso do solo e transporte, e políticas do funcionamento da sociedade em geral" (Geurs e Wee, 2004). Segundo Litman (2012) acessibilidade se refere à facilidade de alcançar bens, serviços, atividades e destinos que juntos são chamados de oportunidades. $\mathrm{O}$ acesso é o objetivo principal das atividades de transporte, exceto a pequena porção de viagens que possui a mobilidade como um fim (caminhadas no parque, cruzeiros, passeios de trem de lazer), em geral, mesmo quando recreativas as viagens geralmente tem um destino. Para Ford et al. (2015) a acessibilidade também capta o esforço necessário para superar a separação espacial entre dois locais, e geralmente se reflete na utilidade associada à viagem entre essas localidades.

Dentre as aplicações dos vários indicadores de acessibilidade encontrados na literatura podem-se citar: (i) a de Wachs e Kumagai (1973), que ilustram em seu trabalho as diferenças de acessibilidade como função da localização espacial da residência e da posição socioeconômica; (ii) a hipótese de Koenig (1977), que usa utilidade para implicar que se o indivíduo numa determinada zona ranqueasse todas as viagens possíveis em ordem decrescente de utilidade, ele viajaria o suficiente para assegurar que a utilidade derivada de fazer a última viagem fosse exatamente igual à desutilidade de não fazê-la; (iii) a de Gutierrez et al. (2010), que propõem uma metodologia para medir spillovers espaciais (benefícios que uma região recebe de desenvolvimentos de infraestrutura construídos em outras regiões) do investimento na infraestrutura de transportes e monetizá-los, distribuindo os custos das infraestruturas previstas de acordo com a distribuição regional dos benefícios potenciais de acessibilidade; (iv) e a de Lima Neto (1982), cujo conceito foi adotado neste artigo, e que trata acessibilidade como um índice de qualidade locacional de atividades, indicando maior ou menor facilidade de aceder às oportunidades, considerando as características do sistema de transporte, a quantidade de atividades com possibilidade de alcance e a localização de tais atividades.

\section{A RMR E A EVOLUÇÃO NO PERFIL DAS VIAGENS PENDULARES}

A Região Metropolitana Recife institucionaliza-se em 1973 pela Lei Federal no 14 (BRASIL, 1973), constituindo-se hoje de 14 municípios: Abreu e Lima, Araçoiaba, Camaragibe, Cabo de Santo Agostinho, Igarassu, Ilha de Itamaracá, Ipojuca, Itapissuma, Jaboatão dos Guararapes, Moreno, Olinda, Paulista, Recife e São Lourenço da Mata. A Figura 1 mostra como estão distribuídos os municípios da RMR. Essa região metropolitana corresponde ao maior aglomerado urbano do Norte-Nordeste, à terceira área metropolitana mais densamente habitada do país, e a quarta maior rede urbana do Brasil em população (IBGE, 2013).
Ocupa $2,81 \%$ do território estadual e concentra $42 \%$ da população pernambucana (IBGE, 2010). De sua população total, 3.589.674 habitantes residem na zona urbana (51\% da população urbana em PE) e 101.383 habitantes na zona rural (5,81\% da população rural do Estado). A capital ocupa $7,2 \%$ da área metropolitana e concentra 41,6 \% dos habitantes da região numa área de $218 \mathrm{~km}^{2}$. A participação relativa da população do Recife na RMR é decrescente ao longo das últimas décadas, reduzindo de $44 \%$ em 1991 para 42,6\% em 2000 e para 41,64\% em 2010 (Bitoun et al., 2013).,

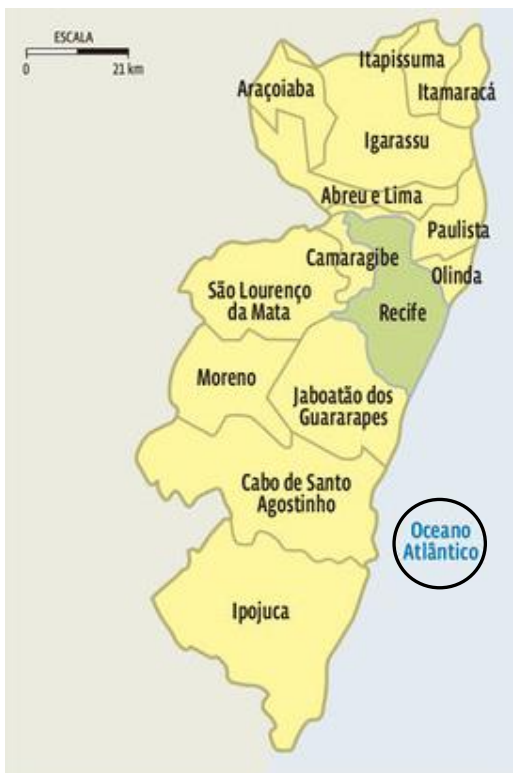

Figura 1. Mapa RMR com destaque para área do CIPS.

A ocupação espacial desse território é caracterizada por uma malha contínua cujos limites político-administrativos municipais são desconsiderados, bem como, pela incorporação de núcleos urbanos isolados, cuja integração à dinâmica de fluxos, funções e relações socioeconômicas é deficiente. Isso se deve aos importantes déficits de infraestrutura, justamente com a forte presença de adensamentos urbanos em áreas de risco. Além disso, a força dos movimentos sociais do Recife, apoiados por vetores progressistas, barram a lógica perversa da segregação espacial dos pobres na área central, como no modelo europeu ou na periferia, como no modelo americano, e geraram locais de resistência, do que resulta um padrão de ocupação urbana, onde áreas pobres e ricas se entrelaçam (Bacelar, 2013; Lima et al., 2014).

Do ponto de vista da mobilidade, observa-se que há mudanças significativas tanto no aumento da frota, quanto no padrão de deslocamentos entre os municípios. Entre os anos de 1997, quando o total de veículos em circulação era de 489.476 e 2010, com 934.881 veículos nas vias da região metropolitana, a frota de veículos na RMR cresceu aproximadamente 5,2 \% ao ano (DETRAN - PE, 2015). Enquanto que a população da RMR cresceu apenas $11 \%$ entre os censos de 2000 e 2010 (Bitoun et al., 2013). Além disto, o número de motocicletas multiplica-se por seis no período, passando de 6,2\% da frota em 1997 para 20,5\% em 2010, enquanto a participação dos automóveis reduz de 77,5\% para 63,5\% (DETRAN-PE, 2015). Esses fenômenos contribuem para o agravamento de problemas sociais nocivos, como a diminuição da demanda por transporte público, em virtude 
Tabela 1. Distribuição de viagens pendulares por matrizes O/D anos 1997 e 2010 Fontes: Pesquisa domiciliar-97 (EMTU, 1998) e Microdados do Censo 2010 (IBGE, 2010)

\begin{tabular}{|c|c|c|c|c|c|c|c|c|c|c|c|c|c|c|c|c|c|c|c|c|c|c|c|c|c|c|}
\hline & \multicolumn{2}{|c|}{ Abreu e Lima } & \multicolumn{2}{|c|}{ Cabo } & \multicolumn{2}{|c|}{ Camaragibe } & \multicolumn{2}{|c|}{ Igarassu } & \multicolumn{2}{|c|}{ Ipojuca } & \multicolumn{2}{|c|}{ Itamaracá } & \multicolumn{2}{|c|}{ Itapissuma } & \multicolumn{2}{|c|}{ Jaboatão } & \multicolumn{2}{|c|}{ Moreno } & \multicolumn{2}{|c|}{ Olinda } & \multicolumn{2}{|c|}{ Paulista } & \multicolumn{2}{|c|}{ Recife } & \multicolumn{2}{|c|}{ S. Lourenço } \\
\hline & 1997 & 2010 & 1997 & 2010 & 1997 & 2010 & 1997 & 2010 & 1997 & 2010 & 1997 & 2010 & 1997 & 2010 & 1997 & 2010 & 1997 & 2010 & 1997 & 2010 & 1997 & 2010 & 1997 & 2010 & 1997 & 2010 \\
\hline breu & $77 \%$ & $43 \%$ & $0 \%$ & $0,9 \%$ & $0 \%$ & $1 \%$ & $3 \%$ & $5 \%$ & $0 \%$ & $0,2 \%$ & $1 \%$ & $0,2 \%$ & $1 \%$ & $1 \%$ & $0 \%$ & $2 \%$ & $0 \%$ & $0 \%$ & $2 \%$ & $4 \%$ & $5 \%$ & $10 \%$ & $11 \%$ & $33 \%$ & $0 \%$ & $0 \%$ \\
\hline Cabo & $0 \%$ & $0 \%$ & $89 \%$ & $74 \%$ & $0 \%$ & $0 \%$ & $0 \%$ & $0 \%$ & $1 \%$ & $11 \%$ & $0 \%$ & $0,0 \%$ & $1 \%$ & $0 \%$ & $3 \%$ & $7 \%$ & $0 \%$ & $0 \%$ & $0 \%$ & $0 \%$ & $0 \%$ & $0 \%$ & $6 \%$ & $8 \%$ & $0 \%$ & $0 \%$ \\
\hline Camar & $0 \%$ & $0 \%$ & $0 \%$ & $0,7 \%$ & $77 \%$ & $42 \%$ & $0 \%$ & $0 \%$ & $0 \%$ & $0,2 \%$ & $0 \%$ & $0,0 \%$ & $0 \%$ & $0 \%$ & $1 \%$ & $2 \%$ & $0 \%$ & $0 \%$ & $0 \%$ & $1 \%$ & $0 \%$ & $1 \%$ & $20 \%$ & $51 \%$ & $2 \%$ & $2 \%$ \\
\hline arassu & $3 \%$ & $4 \%$ & $0 \%$ & $0,5 \%$ & $0 \%$ & $0 \%$ & $85 \%$ & $65 \%$ & $0 \%$ & $0,2 \%$ & $0 \%$ & $0,4 \%$ & $2 \%$ & $3 \%$ & $0 \%$ & $1 \%$ & $0 \%$ & $0 \%$ & $1 \%$ & $3 \%$ & $2 \%$ & $6 \%$ & $7 \%$ & $17 \%$ & $0 \%$ & $0 \%$ \\
\hline pojuca & $0 \%$ & $0 \%$ & $5,5 \%$ & $2,0 \%$ & $0 \%$ & $0 \%$ & $0 \%$ & $0 \%$ & $88 \%$ & $97 \%$ & $0 \%$ & $0,0 \%$ & $0 \%$ & $0 \%$ & $1,5 \%$ & $0 \%$ & $0 \%$ & $0 \%$ & $0 \%$ & $0 \%$ & $0 \%$ & $0 \%$ & $4,5 \%$ & $1 \%$ & $0 \%$ & $0 \%$ \\
\hline Itamaracá & $1 \%$ & $1 \%$ & $1 \%$ & $0,3 \%$ & $1 \%$ & $0 \%$ & $2 \%$ & $3 \%$ & $1 \%$ & $0,4 \%$ & $74 \%$ & $79 \%$ & $1 \%$ & $2,5 \%$ & $1 \%$ & $0 \%$ & $1 \%$ & $0 \%$ & $1 \%$ & $1 \%$ & $4 \%$ & $1 \%$ & $11 \%$ & $12 \%$ & $1 \%$ & $0 \%$ \\
\hline apissuma & $2 \%$ & $1 \%$ & $0 \%$ & $0,3 \%$ & $0 \%$ & $0 \%$ & $7 \%$ & $14 \%$ & $0 \%$ & $0,1 \%$ & $2 \%$ & $7,8 \%$ & $82 \%$ & $57 \%$ & $0 \%$ & $1 \%$ & $0 \%$ & $0 \%$ & $1 \%$ & $3 \%$ & $1 \%$ & $3 \%$ & $5 \%$ & $13 \%$ & $0 \%$ & $0 \%$ \\
\hline boatão & $0 \%$ & $0 \%$ & $1 \%$ & $3,0 \%$ & $0 \%$ & $0 \%$ & $0 \%$ & $0 \%$ & $0 \%$ & $1,5 \%$ & $0 \%$ & $0,0 \%$ & $0 \%$ & $0 \%$ & $78 \%$ & $55 \%$ & $0 \%$ & $0 \%$ & $0 \%$ & $1 \%$ & $0 \%$ & $0 \%$ & $21 \%$ & $39 \%$ & $0 \%$ & $0 \%$ \\
\hline Moreno & $0 \%$ & $0 \%$ & $0 \%$ & $3,5 \%$ & $0 \%$ & $0 \%$ & $0 \%$ & $0 \%$ & $0 \%$ & $1,1 \%$ & $0 \%$ & $0,0 \%$ & $0 \%$ & $0 \%$ & $6 \%$ & $11 \%$ & $83 \%$ & $54 \%$ & $0 \%$ & $1 \%$ & $0 \%$ & $0 \%$ & $11 \%$ & $29 \%$ & $0 \%$ & $0 \%$ \\
\hline Olinda & $0 \%$ & $1 \%$ & $0 \%$ & $0,6 \%$ & $0 \%$ & $0 \%$ & $0 \%$ & $0 \%$ & $0 \%$ & $0,2 \%$ & $0 \%$ & $0,0 \%$ & $0 \%$ & $0 \%$ & $1 \%$ & $2 \%$ & $0 \%$ & $0 \%$ & $74 \%$ & $47 \%$ & $1 \%$ & $3 \%$ & $24 \%$ & $46 \%$ & $0 \%$ & $0 \%$ \\
\hline Paulista & $1 \%$ & $2 \%$ & $0 \%$ & $0,6 \%$ & $0 \%$ & $0 \%$ & $0 \%$ & $1 \%$ & $0 \%$ & $0,3 \%$ & $0 \%$ & $0,0 \%$ & $0 \%$ & $0 \%$ & $0 \%$ & $2 \%$ & $0 \%$ & $0 \%$ & $6 \%$ & $10 \%$ & $70 \%$ & $43 \%$ & $23 \%$ & $41 \%$ & $0 \%$ & $0 \%$ \\
\hline Recife & $0 \%$ & $0 \%$ & $0 \%$ & $0,8 \%$ & $0 \%$ & $0 \%$ & $0 \%$ & $0 \%$ & $0 \%$ & $0,6 \%$ & $0 \%$ & $0,0 \%$ & $0 \%$ & $0 \%$ & $2,5 \%$ & $3,5 \%$ & $0 \%$ & $0 \%$ & $1 \%$ & $1 \%$ & $0 \%$ & $1 \%$ & $96 \%$ & $93 \%$ & $0 \%$ & $0 \%$ \\
\hline ão Lourenço & $0 \%$ & $0 \%$ & $0 \%$ & $1,0 \%$ & $9 \%$ & $7 \%$ & $0 \%$ & $0 \%$ & $0 \%$ & $0,2 \%$ & $0 \%$ & $0,0 \%$ & $0 \%$ & $0 \%$ & $1 \%$ & $2 \%$ & $0 \%$ & $0 \%$ & $0 \%$ & $1 \%$ & $0 \%$ & $0 \%$ & $3 \%$ & $42 \%$ & $87 \%$ & $47 \%$ \\
\hline
\end{tabular}

da migração dos usuários para a motocicleta, juntamente com aumento da quantidade de motociclistas envolvidos em acidentes graves. $\mathrm{O}$ índice de mortalidade de motociclistas cresce $875 \%$ entre o ano de 1996 (0,4/100 mil habitantes) e 2006 (3,9/100 mil habitantes) em Pernambuco (Silva et al., 2011).

Entre 1997 e 2010 os deslocamentos dentro do mesmo município apenas aumentam nos municípios de Ipojuca e de Itamaracá. Diminuem pouco no Recife (3\%) e no Cabo (15\%). Nos demais diminuem em média 30\%, como pode ser observado na Tabela 1 denotando que houve importantes modificações nas localizações dos empregos.

Com relação à variação de viagens atraídas, Recife é a campeã atraindo, em 2010, 186\% mais deslocamentos do que em 1997, ressaltando um aumento da sua centralidade como geradora de empregos. Ipojuca também apresenta aumento significativo (23,4\%). O município do Cabo de Santo Agostinho não aumenta, mas é um dos que menos sofre redução (9\% apenas, numa média de $22 \%$ ). Os únicos municípios que atraem deslocamentos de todos os outros municípios da região metropolitana em 2010 são a capital, Recife, e os municípios do Cabo de Santo Agostinho e Ipojuca (fato que não ocorria em 1997) reforçando a importância de se pensar uma política de mobilidade adequada envolvendo esses dois municípios.

\subsection{A economia pernambucana e o CIPS}

A RMR concentra a maior parte do PIB estadual $(65,1 \%)$. O surgimento de novas atividades (petróleo \& gás, construção naval, indústria automobilística, siderúrgica, farmacoquímica), bem como, a redefinição de segmentos tradicionais (produtos alimentares e bebidas, têxtil, metalmecânica, material elétrico), alavancaram a economia pernambucana, cujo crescimento tem sido maior que o nacional. Entre 1997 e 2011, o PIB pernambucano cresce 34\% acima do PIB nacional (CONDEPE/FIDEM, 2014). Grande parte deste destaque é atribuída às oportunidades criadas pelos investimentos fomentadas pelo Complexo IndustrialPortuário de Suape (CIPS), situado nos municípios de Ipojuca e do Cabo de Santo Agostinho na RMR, como pode ser visto na Figura 1. É considerado ainda, como um dos principais polos de investimento do país. Suas 120 empresas já instaladas e outras 50 em implantação em 13,5 mil hectares constituem o principal polo de atração de negócios do Nordeste brasileiro, gerando atualmente 25 mil empregos diretos (GOVERNO DE PERNAMBUCO, 2014).

A economia açucareira dominava a região onde se situa o CIPS até a década de 1990. Desde então, a região vêm sofrendo um significativo processo de transformação no seu perfil econômico em virtude dos importantes investimentos públicos e privados resultantes do grande polo industrial e logístico ali instalado. A demanda por mão de obra cresce ano a ano, principalmente enquanto perdurar a fase de implantação das obras civis das instalações industriais e da construção das infraestruturas viárias, de energia e portuárias demandadas. O perfil profissional e o nível de capacitação da mão de obra disponível nos municípios do entorno têm produzido uma forte migração de trabalhadores de outras regiões e de outras cidades da RMR. Este fato tem gerado grandes demandas de mobilidade não suportadas pelo sistema viário e de transporte existente e cuja expansão, apesar de planejada, com financiamento de $\mathrm{R} \$ 920$ milhões em infraestruturas portuárias, rodoviárias, ferroviárias, retroportuárias não foi executada plenamente. A via rodoviária expressa foi concluída, mas a obra ferroviária não foi implementada em completude (BNDES, 2012).

Para agravar essa situação, em 1997 apenas 0,003\% dos habitantes do Recife trabalhava em Ipojuca e $0,16 \%$ no Cabo de Santo Agostinho, número que cresceu para 0,53\% e $0,71 \%$ em 2010 . O total de habitantes da região metropolitana que se deslocava para o Cabo de Santo Agostinho ou Ipojuca passa de 5,3\% para 7,8\% entre 1997 e 2010.

Apesar desse aumento significativo no número de viagens destinadas à região, existe ainda uma grande deficiência na oferta de transporte público, especificamente para atender ao CIPS. A partir do mapa ilustrado na Figura 2 observa-se que a rede de transporte público existente atende o interior de Suape através de uma linha de ônibus (Suape-TI Cabo), que realiza apenas 14 viagens diárias. Há, no entanto, uma razoável frequência de linhas de ônibus que atendem às localidades situadas ao sul (Camela, N.S. do Ó e Ipojuca), apenas garantindo uma acessibilidade lindeira às rodovias PE-060 e PE-028, sem penetrar nas áreas industriais de maior demanda de empregos. Essas linhas alimentadoras se conectam ao Terminal Integrado do Cabo de Santo Agostinho, de onde é possível ter acesso ao sistema SEI (Sistema Estrutural Integrado). Desse terminal pode-se atingir qualquer ponto da RMR pagando apenas uma passagem através de duas linhas de ônibus (TI-Cabo e TI-Cabo/TICajueiro) ou por uma linha de VLT (Cabo - Cajueiro Seco) e desse ponto se interligando à Linha Sul do Metrô. Por dia, utilizam o TI do Cabo 8.975 usuários, quantidade ínfima quando comparada ao número estimado de cerca de setenta mil trabalhadores que se deslocam para Suape todos os dias (GRANDE RECIFE, 2015). 


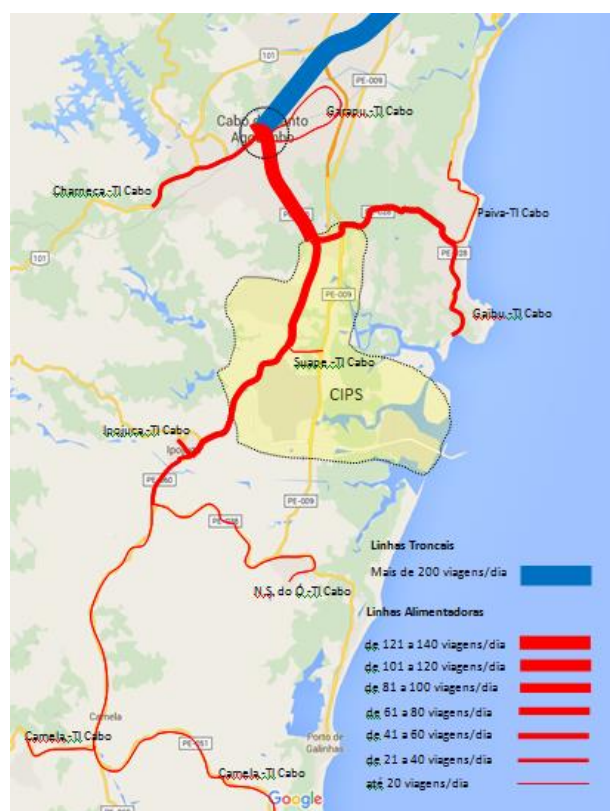

Figura 2. Mapa da rede de transporte público no entorno do CIPS.

Em relação ao modo rodoviário, 50 mil veículos circulam por dia nos segmentos mais carregados. Apenas no Porto de Suape são mais de 3.000 caminhões e cerca de 800 ônibus fretados para transporte de funcionários, Do total de veículos fretados, quase $74 \%$ concentram-se nos horários de pico da manhã e $84 \%$ no pico da tarde (Santos et al., 2014). Por isso, apesar do conjunto de rodovias arteriais e coletoras de acesso, engarrafamentos quilométricos e tempos crescentes de viagem estão se tornando rotina em muitas horas durante os dias úteis. De acordo com Meira et al. (2012) em 2009 os níveis de serviço na região variavam entre D e E na maior parte dos dias úteis. Nos anos seguintes, com a intensificação das obras, o quadro se agravou passando ao nível de serviço $\mathrm{F}$, nos trechos mais críticos das rodovias. Assim, embora as vantagens econômicas propiciadas pela criação deste polo sejam inegáveis, as externalidades por ele produzidas, principalmente no que tange à mobilidade, também o são.

\section{METODOLOGIA}

Com o objetivo de englobar localização, distribuição e intensidade das atividades, assim como, as características do sistema de transportes, bem como mensurar a acessibilidade de cada município da Região Metropolitana do Recife, para dados recentes de 2010 e compará-los com o cenário presente em 1997, criou-se um indicador com base no proposto por Lima Neto (1982), para a cidade do Recife. Os seguintes procedimentos são adotados durante a realização dos cálculos:

\subsection{Indicadores}

O indicador elaborado permite considerar as características do tempo de deslocamento entre os municípios, características da rede e do sistema de transportes, e a distribuição espacial das atividades na RMR, avaliando a interação entre transporte e o uso do solo, tendo sido inspirado nos indicadores de acessibilidade de Mäcke (1974) e de
Wachs e Kumagai (1973). A informação disponível também foi um fator importante para elaboração deste indicador.

$$
Q_{i p}=\left(\sum_{j=1}^{n} X_{i j p} 10^{3}\left(W_{i j p}\right)^{-1}\right)
$$

Sendo:

$Q_{i p}=$ índice de qualidade locacional ou acessibilidade do município de destino i para o propósito $\mathrm{p}$;

$i$ = índice numérico do município de destino;

$p=$ propósito da viagem

$j=$ índice do intervalo de tempo de deslocamento

$X_{i j p}=$ quantidade percentual ou intensidade de estruturas no município

$W_{i j p}=$ função de impedância ou dificuldade de acessibilidade ao município para o propósito $\mathrm{p}$

O cálculo da variação do nível de acessibilidade nos dois anos avaliados foi feito com base no índice anterior, mas considerando, os municípios de origem e de destino.

$$
Z_{f i}=\sum_{i=1}^{n} W_{i p A}-\sum_{i=1}^{n} W_{i p B}
$$

Onde:

$Z_{f i}=$ variação do tempo de deslocamento no município i para o propósito p;

$f=$ tipo de relação com o município i

$i$ = índice numérico do município de destino;

$p=$ propósito da viagem

$A=$ ano base

$B=$ ano atual

$W_{i p}=$ função de impedância ou dificuldade de acessibilidade ao município para o propósito $\mathrm{p}$

\subsection{Levantamento de dados}

Depois da elaboração dos indicadores, passa-se à etapa de obtenção dos dados necessários para calibrar o modelo: número de viagens atraídas por cada destino, o indicador socioeconômico que representa a estrutura ou atividade localizada em cada zona de destino, e o parâmetro utilizado na função de impedância, o tempo de deslocamento por motivo trabalho. A razão da escolha dos instantes temporais e motivo da viagem como sendo "trabalho" são os dados disponíveis.

Para o ano de 1997 foi utilizada a última pesquisa de origem e destino domiciliar para RMR elaborada para a EMTU- Recife (1998) e para o PDTU (Plano Diretor de Transporte Urbano) cujos microdados foram obtidos junto ao grupo de pesquisa em transportes da Universidade Federal de Pernambuco. Para o ano de 2010 foram utilizados os dados do censo demográfico obtidos diretamente do IBGE. Esse censo aborda pela primeira vez o tempo de deslocamento do indivíduo até o emprego, possibilitando uma maior gama de pesquisas em transportes utilizando microdados demográficos.

\subsection{Função de impedância}

A medida da acessibilidade foi feita através da frequência de viagens segundo classes de gasto (por exemplo, tempo ou distância), seguindo o conceito de Mäcke (1974) denominado função de impedância. O propósito de viagem 


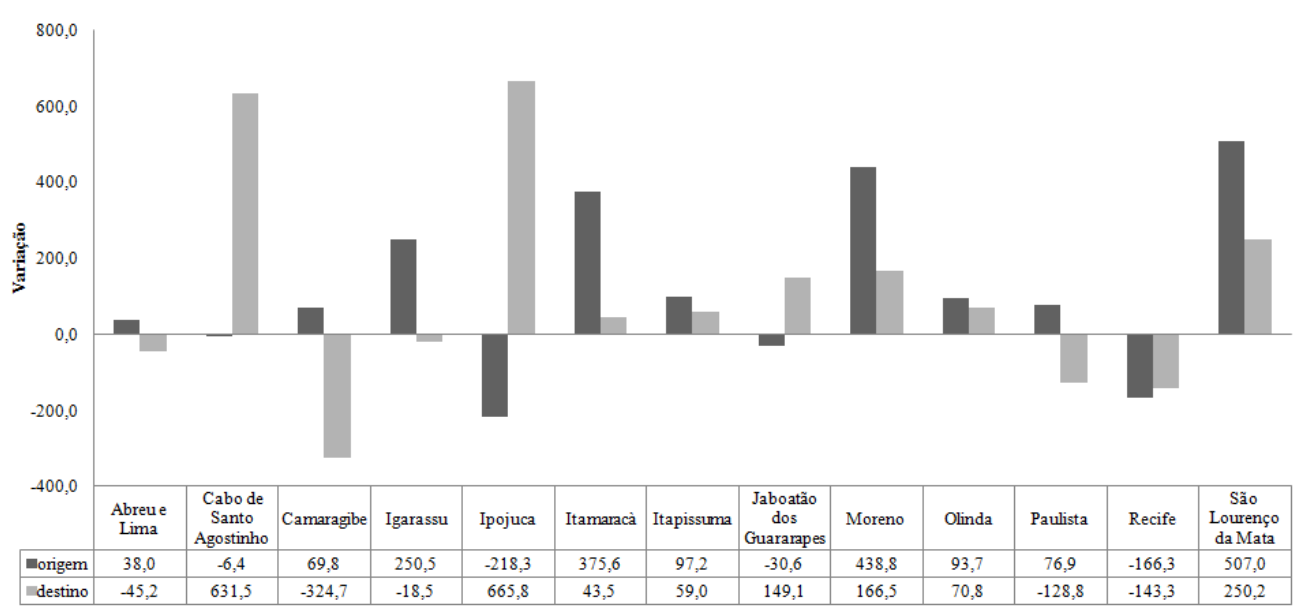

Gráfico 1. Diferença de acessibilidade entre 1997-2010 para origem e destino

escolhido é "trabalho" e a impedância o tempo de deslocamento até o trabalho para cada indivíduo, considerando a População Economicamente Ativa (PEA) que apresentava um comportamento de deslocamento pendular ao trabalho, ou seja, ia e retornava no mesmo dia. Parte-se então, para a determinação das funções de impedância. $\mathrm{O}$ índice de qualidade locacional é calculado considerando as viagens atraídas. Também é indexada a variação de acessibilidades com relação à origem e ao destino para os municípios.

As viagens são agrupadas segundo classes de tempo de deslocamento definidas pelo IBGE (2010). A classe 1 representa viagens com tempo de deslocamento menor que 5 minutos, a classe 2 representa as viagens entre 5 e $30 \mathrm{mi}-$ nutos, a 3 engloba as viagens com duração entre 30 minutos e 1 hora e a 4 entre 1 e 2 horas e a 5 mais de 2 horas. O número de viagens atraídas àquele município é então ponderado utilizando a média dos minutos despendidos em cada classe.

Os dados de 2010 do Censo apenas permitem analisar do ponto de vista viagens com propósito de emprego. A cidade de Araçoiaba foi desconsiderada por inconsistência dos dados sendo, portanto, analisados os dados de 13 dos 14 municípios da RMR.

\section{ANÁLISE DOS RESULTADOS}

Este trabalho examina o nível de acessibilidade de treze dos quatorze municípios da Região Metropolitana do Recife com um recorte sobre o impacto causado pela criação de um território gerador de viagens em uma área previamente dedicada à agroindústria. Nesse objetivo, o indicador foi adaptado possibilitando uma análise longitudinal com base na variação do número de empregos e tempo de viagem ao trabalho entre nos anos de 1997 e 2010, conforme a metodologia apresentada no item 4. Primeiramente, avalia-se especificamente o impacto da presença de um complexo de empreendimentos classificados como PGV usando o indicador proposto calibrado pela variação percentual do número de viagens geradas e atraídas nos treze municípios. O Gráfico 1 apresenta a variação entre 1997 e 2010 do nível de acessibilidade dos habitantes de cada município identificado (origem) e das pessoas que trabalham em cada um dos municípios (destino).
Considerando a origem, a partir da década de 2000, as cidades mais próximas ao CIPS apresentam um crescimento bastante acelerado, que não foi acompanhado na mesma intensidade pelas infraestruturas de transportes. É possível notar que os únicos municípios que variam negativamente com relação ao tempo de deslocamento ao trabalho são os municípios da área sul da RMR, mais influenciados pelo complexo portuário. Este fato deve-se a que as pessoas que moram nestes municípios passam a despender menos tempo de deslocamento do que as demais. O aumento do emprego local, em Ipojuca e no Cabo de Santo Agostinho, pode ser a causa desse fenômeno. Em 2010, 98\% dos habitantes de Ipojuca e $85 \%$ dos habitantes do Cabo de Santo Agostinho trabalhavam em um dos dois municípios.

No caso do município de Jaboatão dos Guararapes, a variação negativa pode ser justificada pela diminuição do tempo médio de viagem dos habitantes dessa zona que trabalhavam na capital (39\%), de 84 para 54 minutos entre os dois instantes temporais.

Na capital Recife, embora cause estranheza, acontece diminuição do tempo de viagem justificada por um decréscimo no tempo das pessoas que moram e trabalham neste município (93\%) de 39 para 33 minutos. Como possíveis causas para essa redução, acontecem no final da década de 2000, a ampliação do metrô para a zona sul do Recife, que representa importante polo atrator de viagens com o propósito trabalho, assim como, mudanças realizadas no tráfego das principais vias desta zona melhorando a fluidez do trânsito. Outra possível causa é o maior adensamento construtivo que permite aproximar as zonas de habitação e trabalho, diminuindo, assim, os tempos de deslocamento.

Do ponto de vista inverso, ou seja, avaliando a variação no nível de acessibilidade entre os anos 1997 e 2010 das pessoas que trabalham em cada município (destino, no Gráfico 1), os municípios do Cabo de Santo Agostinho e Ipojuca também se destacam. Um indicativo de que as pessoas dos demais municípios da RMR que se deslocam pendularmente com destino a estas cidades apresentam um incremento significativo em seus tempos médios de deslocamento. Tal aumento se justifica por duas razões: um aumento elevado no número de viagens diárias para a região (23,4\% em Ipojuca) e a ausência de uma rede viária e de serviços de transportes adequada.

O presente trabalho também se propõe a calcular um índice de qualidade locacional dos municípios estudados. Este cálculo é feito com os dados da base do IBGE de 2010 
para viagens atraídas aos municípios com o propósito trabalho. Os resultados podem ser observados na Tabela 3. O indicador considera o número percentual de viagens atraídas e o tempo de deslocamento à região. Como esperado a capital, Recife, se destaca como o município mais acessível para fins empregatícios. Os municípios de Itamaracá, Itapissuma, e Igarassu apresentaram um bom desempenho pelo baixo tempo de deslocamento total, visto que apenas trabalhadores destas cidades permutam entre si para fins de trabalho e como estão localizadas geograficamente próximas uma das outras o seu tempo total de deslocamento é baixo, alavancando o indicador. À exceção desses outliers, os municípios que se destacam são justamente os do Cabo de Santo Agostinho e o de Ipojuca - onde se situa a maioria das empresas atraídas pelo CIPS, representando um alto nível de atratividade em emprego, visto que atualmente indivíduos de todos os municípios da RMR se deslocam em sua direção, diferentemente do observado em 1997. Dos habitantes do Recife, em 1997, apenas 0,003\% trabalhava em Ipojuca e 0,16\% no Cabo de Santo Agostinho, contra 0,53\% e $0,71 \%$ em 2010 .

Tabela 2. Índice de qualidade locacional em 2010, cálculos autores com dados do IBGE

\begin{tabular}{ll}
\hline Município & Índice \\
\hline Abreu e Lima & 21,49 \\
Cabo de Santo Agostinho & 28,23 \\
Camaragibe & 18,51 \\
Igarassu & 33,58 \\
Ipojuca & 33,48 \\
Itamaracá & 41,23 \\
Itapissuma & 28,84 \\
Jaboatão dos Guarapes & 23,98 \\
Moreno & 22,10 \\
Olinda & 23,05 \\
Paulista & 22,55 \\
Recife & 79,97 \\
São Lourenço da Mata & 19,05 \\
\hline
\end{tabular}

É possível afirmar, portanto, que a implantação do Complexo Industrial Portuário de Suape, considerado, segundo a terminologia adotada neste artigo, um território gerador de viagens, influencia a dinâmica social e econômica dos habitantes dos municípios que compõem a região, bem como de pessoas de todos os municípios da RMR que se destinam ao CIPS pendularmente. O tempo médio de deslocamento em direção a estas cidades no período analisado aumenta significativamente, passando de 67 para 85 minutos (Cabo de Santo Agostinho) e de 68 para 83 minutos (Ipojuca).

\section{CONSIDERAÇÕES FINAIS}

Claramente a instalação do CIPS na região sul da RMR traz grandes mudanças, não apenas para a localidade onde se situa, mas também para o restante da metrópole. Isso pode ser observado pela intensificação dos deslocamentos de pessoas e veículos para essa área, como demonstra a enorme diferença entre os tempos de deslocamento para os municípios do Cabo de Santo Agostinho e Ipojuca entre os anos de 1997 e 2010.

Além disso, os resultados encontrados nesse trabalho indicam que o índice de acessibilidade para os moradores da região melhora muito, ao mesmo tempo em que a sua renda per capita apresenta a maior variação entre os anos de 2000 e 2010 na RMR, crescendo 73\% em Ipojuca e 75\% no Cabo de Santo Agostinho (IBGE, 2013). Esses números indicam que os trabalhadores da região foram absorvidos pelas indústrias adjacentes, contradizendo a hipótese de Cavalcanti (2004). Esse fato é de grande relevância dada que a diminuição da desigualdade social é fator chave para o desenvolvimento sustentável em uma localidade.

É importante ressaltar que a região apresenta para os habitantes dos outros municípios, que se deslocam diariamente por motivos de trabalho, um tempo excessivamente elevado, com uma média de 93 minutos de tempo deslocamento. Isso significa um acréscimo de 3 horas diárias na jornada de trabalho desses indivíduos que, por muitas vezes, já chegam ao trabalho fadigados, devido ao longo tempo de percurso. Das ações planejadas pelo Governo do Estado que poderiam impactar as condições de mobilidade dos trabalhadores foram implantadas e estão em operação desde 2010, apenas as obras rodoviárias representadas pelas melhorias de capacidade na Estrada da Batalha, em Jaboatão dos Guararapes, uma das vias de acesso aos CIPS e a implantação da rodovia pedagiada denominada Express Way Suape. No entanto, ações de melhorias nos transportes públicos não foram efetivadas, o que propicia o grande crescimento do transporte de trabalhadores por fretamento diretamente pelas empresas instaladas.

Existe, portanto, a necessidade de monitorar a acessibilidade do CIPS como território gerador de viagens concomitantemente ao incremento de empresas em atividade, de forma que uma ação conjunta entre o fomento, a instalação de atividades e a melhoria da acessibilidade possam promover a sustentabilidade do complexo, garantindo rentabilidade aos altos recursos investidos. Ou seja, sugere-se que os investimentos na instalação de novos empreendimentos devam ser acompanhados simultaneamente por investimentos em transportes, para que o processo melhore as condições de acessibilidade hoje observadas para os demais municípios.

Ainda segundo este aspecto existe um estudo interessante da equipe de planejamento do METROREC de reativar uma antiga linha de trem utilizando a tecnologia VLT integrada ao metrô. A linha proposta parte do Forte do Brum, junto ao Porto do Recife passando próximo ao terminal de passageiros do 'Cais de Santa Rita', seguindo até a Estação Rodoferroviária de Massangana no CIPS, com tempo total estimado em 73 minutos (Santos et al., 2014). Essa proposta possibilita a redução do tempo de viagem dos trabalhadores com origem no centro e na zona norte da RMR com destino aos empregos em Suape.

Relativamente à utilização dos indicadores de acessibilidade, existe uma multiplicidade de aplicações e a interação entre o transporte e uso do solo pode ser medida de forma satisfatória por meio deles. Destaca-se a facilidade com a qual este indicador pode ser aplicado, sendo todos os cálculos realizados em planilhas eletrônicas EXCEL.

Para determinar os impactos agregados causados pela implantação de PGVs esse indicador é considerado satisfatório. Entretanto, seria muito interessante aplicar este indicador para uma pesquisa zona-zona para analisar mais minuciosamente as variações de acessibilidade em áreas menores e a sua relação com o uso e ocupação do solo. Infelizmente, os dados disponíveis não permitem tal análise, uma 
vez que o CENSO 2010 apenas informa o município, mas não a zona onde o indivíduo trabalha, diferentemente da última pesquisa O/D domiciliar de 1997 utilizada para comparações como ano base neste trabalho.

Dito isso, considera-se que o Complexo Industrial e Portuário de Suape é um importante território gerador de viagens, pois o impacto causado pela implantação de um conjunto de PGVs condiz com a definição de Kneib (2004) que afirma serem caracterizados como PGVs empreendimentos que afetem a totalidade da estrutura urbana da área onde são instalados, podendo contribuir para a criação de novas centralidades. Conjuntamente, sua existência modifica a dinâmica social dos municípios que o abrigam, melhorando tanto o tempo de deslocamento desses habitantes, quanto a sua renda.

\section{REFERÊNCIAS}

Andrade, M. O.; Meira, L. H.; e Maia, M. L. A. Aguilera, A. e Mignot, D. (2004) Urban sprawl, polycentrism and commuting. A comparison of seven French urban areas. Urban Public Economics Review. No. 001.

Ben-Akiva, M., Lerman, S.R., (1979) Disaggregate Travel and Mobility Choice Models and Measures of Accessibility. In: Hensher, D.A., Stopher, P.R., (Eds.), Behavioural Travel Modeling, Croom Helm, Andover, Hants, 654-679.

Bitoun, J., Miranda,L., Souza, M.A.A., Lyra, M.R.S.B. (2013) Região Metropolitana do Recife no Contexto de Pernambuco no Censo 201. Observatório das Metrópoles. Disponível em: http://www.observatoriodasmetropoles.net/download/Texto_BO LETIM_RECIFE_FINAL.pdf Acesso: 30/04/2015

BNDES (2012) BNDES aprova R\$ 920 milhões para infraestrutura no complexo industrial portuário de Suape. Disponível em:

http://www.bndes.gov.br/SiteBNDES/bndes/bndes_pt/Institucion al/Sala_de_Imprensa/Noticias/2012/todas/20120914_suape.html. Acesso: 28/12/2015

Burns, L.D. (1979) Transportation, Temporal And Spatial Components Of Accessibility. Lexington Books, Lexington Toronto.

Cavalcanti, J.C. (2004) Educação Em Pernambuco: O Modelo Tem Que Mudar? Disponível em:

http://www.economia.pe.gov.br. Acesso: 10 Jul. 2014.

Cervero, R. (1996) Jobs-housing balance revisited: trends and impacts in the San Francisco Bay Area. Journal of the American Planning Association 62 (4), 492-511. DOI: http://dx.doi.org/10.1080/01944369608975714

Cervero, R., \& Day, J. (2008). Residential relocation and commuting behavior in Shanghai, China. Berkeley: UC Berkeley Centre for Future Urban Transport

CONDEPE/FIDEM (2014) PIB Estadual. Disponível em $<$ http://www.condepefidem.pe.gov.br/web/condepefidem/estadual $>$. Acesso: 11/07/2014

Cunha, M. J. T., Maia, M. L. A., Lima Neto, O. C. C. (2004) Acessibilidade, Transporte e Reestruturação Urbana. Anais do XVIII Congresso de Pesquisa e Ensino em Transportes, ANPET, Florianópolis, v. 1, p. 748-759.
DETRAN (2015) Estatísticas atuais. Disponível em: http://www.detran.pe.gov.br/index.php?option=com_content\&vi ew $=$ article $\&$ id $=36 \&$ Itemid $=72$

EMTU (1998) Pesquisadomiciliar-97 - Região Metropolitana Do Recife. Empresa Metropolitana De Transportes Urbanos De Recife. Recife.

Ewing, R. (1997) Is Los Angeles-style sprawl desirable? Journal of the American Planning Association 63 (1), 107-126. DOI: $10.1080 / 01944369708975728$

Ford, A. C., Barr, S. L., Dawson, R. J., \& James, P. (2015). Transport Accessibility Analysis Using GIS: Assessing Sustainable Transport in London. ISPRS International Journal of Geo-Information, 4(1), 124-149. DOI:10.3390/ijgi4010124

IBGE (2010) Censo 2010. Disponível em:< http://www. censo2010. ibge. gov. br/>. Acesso: 25/mai/2014.

IBGE (2013) Estimativas populacionais para os municípios brasileiros em 01.07.2013. Disponível em: http://www.ibge.gov.br/home/estatistica/populacao/estimativa20 13/estimativa_dou.shtm. Acesso: 03/jun/2014

Geurs, K.T., Wee, B. Van, (2004) Accessibility Measures a Literature Review. Journal of Transport Geography 12. Pp 127140. Elsevier. DOI:10.1016/j.jtrangeo.2003.10.005

Gordon, P., Richardson, H.W (1996). Beyond Polycentricity: the dispersed metropolis, Los Angeles, 1970-1990. Journal of American Planning Association 62 (3). DOI: $10.1080 / 01944369608975695$

GOVERNO DE PERNAMBUCO (2014) Desenvolvimento econômico. Disponível em: http://www.pe.gov.br/governo/focosestrategicos/desenvolvimento-economico/>. Acesso em: $11 / 06 / 2014$

Goldner, L.G.; Westphal, D.; Pinto de Freitas, I.M.; Santos, D.V.C. Polos múltiplos geradores de viagens (PMGV) (2010) Revista Transportes v. 18, n. 1. DOI: http://dx.doi.org/10.14295/transportes.v18i1.389

Grande Recife (2015) Terminal integrado do cabo. Disponível em: http://www.granderecife.pe.gov.br/web/ granderecife/terminal-integrado-do-cabo. Acesso em: 28/12/2015.

Gutierrez, J., Condeço-Melhorado, A., Matin, J.C. (2010) Using accessibility indicators and GIS to assess spatial spillovers of transport infrastructure investment. Journal of Transport Geography. Vol 18, Issue 1, January 2010, Pages 141-152. DOI:10.1016/j.jtrangeo.2008.12.003

Hansen, W. G. (1959). How accessibility shapes land use. Journal of the American Institute of planners, 25(2), 73-76. DOI:10.1080/01944365908978307

Kneib, E. C., \& Silva, P. C. M. (2004). Caracterização de empreendimentos geradores de viagens: contribuição conceitual à análise de seus impactos no uso, ocupação e valorização do solo urbano. XIX ANPET, 1, 792-803.

Kneib, E.C. (2008) Subcentros Urbanos: Contribuição Conceitual e Metodológica à Sua Definição e Identificação para Planejamento de Transportes. Tese De D.Sc. Universidade de Brasília.

Koenig,G. (1977) Les indicateurs d'accessibilites dans les studes urbaines: de la theorie a la practique. Revue Generale des Routes et des Aerodromes. N 533. Pg 5-23. 
Levinson, D.M.; Kumar, A. (1994) The Rational Locator: Why Travel Times Have Remained Stable. Journal of the American Planning Association, 60: 319-332.

DOI:10.1080/01944369408975590

Lima, J.H.; Maia, M.L.A. (2014) Renda E Tempo De Deslocamento Pendular Na RMR: Quais As Causas Da Relação De Não Monotonicidade Para A População De Baixa Renda? Anais do XVIII Congresso Latino Americano de Transporte Urbano, CLATPU, Rosário, Argentina.

Lima Neto, O.C.C. (1982) Möglichkeiten Und Grenzen Der Übertragung Von Zusammenhängen Und Modellen In Der Grobstädtischen Verkehrsplanung Der Bundesrepublik Deutschland Auf Entwicklungsländer - Dargestellt Na Beispiel De Brasilianischen Stadt Recife. Tese De Doutorado, Universidade Técnica Da Renânia Do Norte, Westfália, Aachen, Alemanha.

Lin, D., Allan, A., \& Cui, J. (2015). The impact of polycentric urban development on commuting behaviour in urban China: Evidence from four sub-centres of Beijing. Habitat International, 50, 195-205. DOI:10.1016/j.habitatint.2015.08.018

McMillen, D.P. (2004) Employment densities, spatial correlation, and subcenters in large metropolitan areas. Journal of Regional Science 44, 225-243. DOI: 10.1111/j.00224146.2004.00335.x

Meira, L.H., Andrade, M.O. e Maia, M.L.A. (2012) Mobilidade Crítica em um território gerador de viagens: O Caso do Complexo Industrial Portuário de Suape, publicado nos Anais do XXVI Congresso da ANPET - Associação Nacional de Ensino e Pesquisa em Transportes, Joinville - SC

Mäcke, P.A. (1974) Personenverkehr In Stadt Und RegionWeiterentwicklung Des Algorithmus Zur Schatzungder Strukturbedingten Nachfrage. In: Stadt Region Land, Schriftenreihe Des Instituts Fur Stadtbauwesen, Rwth Aachen, Heft 30

Silva, P.H., Lima, M.L.C, Moreira, R.S., Souza, W.V., Cabral, A.(2011). Estudo espacial da mortalidade por acidentes de motocicleta em Pernambuco. Rev Saude Publica, 45(2), 409-15. http://dx.doi.org/10.1590/S0034-89102011005000010.

Perroux, F. (1962). Le capitalisme: Que sais-je. PUF, Paris.

PORTOGENTE (2014) Porto de Suape. Portopédia: Tudo sobre transportes, logísticas, comércio e turismo. Disponível em: http://portogente.com.br/portopedia/porto-de-suape-80272, acesso em: $14 /$ jul/2014

REDE, Rede Ibero-Americana De Estudos De Pólos Geradores De Viagens (2005) Relatório Da $1^{a}$ Reunião De Trabalho. Universidade Federal Do Rio De Janeiro. Disponível em: http://Redpgv.Coppe.Ufrj.Br/Arquivos/1areuniao_Relatorio_Abr il_De_2005.Pdf>, acesso em 30/jun/2014

REDPGV (2010) O Que É Um Pgv?Rede Ibero-Americana De Estudo Em Polos Geradores De Viagens. Disponível Em: <Http://Redpgv.Coppe.Ufrj.Br>. Acesso Em: 07/Jul/2014

Rocha, M.H., Sales,A., Ramos,F. (2007) A Implantação De Uma Refinaria De Petróleo Em Suape-Pe: Uma Avaliação Dos

Impactos Socioeconômico-Ambientais A Partir Da Interpretação De Agendas 21 Locais. Disponível em:

<http://www.ecoeco.org.br/conteudo/publicacoes/encontros/vii_e n/mesa2/trabalhos/uma_avaliacao_qualitativa_dos_impactos_ da_implantacao_de_uma_refinaria.pdf $>$. Acesso em: 08/jul/2014.
Saquet, M. A. (2011). Abordagens e concepções de território e territorialidade. Revista Geográfica de América Central, 2 (47E).

Schwanwn, T.; Dieleman, F.M.; Dijst, M. (2001) Travel behavior in Dutch monocentric and polycentric urban systems. Journal of Transportation Geography 9, 173-186. DOI:10.1016/S09666923(01)00009-6

Santos, J.J, Andrade, M.O, Brasileiro, A. (2014) Aproveitamento de antigos ramais ferroviários com adaptação para VLT para atender a novos polos geradores de viagem na RMR Anais do XVIII Congresso Latino Americano de Transporte Urbano, CLATPU, Rosário, Argentina.

Wachs, M., Kumagai, T.G. (1973) Physical Accessibility as a Social Indicator. So\&-Econ. Plan. Sci. Vol. 7, 437-456. Pergamon Press. DOI:10.1016/0038-0121(73)90041-4

Zhao, P., Lu, B., \& Roo, G. (2010). Urban expansion and transportation: the impact of urban form on commuting patterns on the city fringe of Beijing. Environment and Planning A, 42(10), 2467e2486. DOI: 10.1068/a4350 